\title{
Transaction Costs in Payment for Environmental Service Contracts
}

\author{
Jeffrey M. Peterson, Craig M. Smith, John C. Leatherman, Nathan P. Hendricks, \\ and John A. Fox
}

June 11, 2014

Payment for environmental service contracts commonly require actions beyond adoption of a practice, such as undergoing specified enrollment procedures, granting consent to being monitored, and paying penalties for violations. These provisions are a bundle of attributes a landholder must accept with contract enrollment, leading to transaction costs in the contracting process. This article develops a principal-agent framework to study the links between these transaction costs and the well-known information asymmetries between the landholders and the government agency offering contracts. Using stated choice data collected from a sample of farmers, we estimate a mixed logit model to quantify the contribution of different contract attributes on contract willingness-to-accept (WTA). More stringent provisions in contracts were found to raise individual WTA by widely differing amounts across farmers, but the average effects imply that overall contract supply is sensitive to stringency. From a series of microsimulations based on the estimated model, we find that transaction costs create a significant drain on the cost-effectiveness of contracting from the agency's point of view, similar in magnitude to the inefficiency created by hidden information. While stringent contractual terms raise program expenditures, they may be justified if they raise compliance rates enough to offset the added cost. We also simulate an implicit frontier to trace out the change in compliance needed to justify a given increase in stringency. For environmental benefits in the range of previous estimates, this analysis suggests that stringent terms would need to substantially raise compliance rates to be cost effective.

Key words: contracts, hidden information, microsimulation, mixed logit, payment for environmental services, transaction costs

JEL codes: Q58, Q52, Q53

Suggested running head: Transaction costs in environmental contracts

Jeffrey M. Peterson is a professor and the Director of Graduate Studies in the Department of Agricultural Economics at Kansas State University. Craig M. Smith is an assistant professor in the Department of Agriculture at Fort Hays State University. John C. Leatherman is a professor, Nathan P. Hendricks is an assistant professor, and John A. (Sean) Fox is a professor, all in the Department of Agricultural Economics at Kansas State University. The authors are grateful to AJAE editor Brian Roe and three anonymous reviewers for helpful comments. This research was funded by USEPA's Science to Achieve Results (STAR) program through Agreement No. RD-831J77401-0, by USEPA's Section 319 and Kansas Water Plan funds provided by the Kansas Department of Health and Environment, and by USDA-NIFA Multistate Project W-2190. Any opinions, findings, conclusions, or recommendations expressed in this publication are those of the authors and do not necessarily reflect the views of the USEPA or the USDA. 
Payment for environmental services (PES) contracts are a common means of acquiring ecosystem goods or services from private landholders. Such contracts are becoming more prevalent globally, with much of the growth coming from environmental markets in developing nations where PES contracts are a traded instrument (Blackman and Woodward 2010; Pattanayak, Wunder, and Ferraro 2010). In the United States, PES contracts are used in a number of the major federal conservation programs in forestry and agriculture (Mercer, Cooley, and Hamilton 2011; Claassen, Cattaneo, and Johansson 2008), in which a government agency is the sole buyer. In these and many other PES settings, enrolled landholders receive a payment in exchange for a practice or change in land use instead of service provision per se, because of the difficulty in measuring environmental services at small scales.

A large literature has addressed the performance of PES schemes, which can be hindered by various factors (Wunder, Engel, and Pagiola 2008). PES contracts are executed in a principalagent setting, where the buyer of contracts is the principal and the landholder selling a contract is an agent. Frictions due to information asymmetries arise because agents hold private information on their individual costs before contracts are signed (Chambers 1992; Ferraro 2008; Fraser 1995; Latacz-Lohmann and Van der Hamsvoort 1997; Peterson and Boisvert 2004; Spulber 1988; Wu and Babcock 1996) and on their compliance during the contract period (Choe and Fraser 1999; Fraser 1995; Hart 2005; Ozanne 2001; Ozanne and White 2008). Even with full compliance, practicebased contracts commonly assume spatially averaged or simulated service provision, which may not be realized on all contracted sites (Cattaneo 2003). Moreover, some of the enrolled landholders may have adopted the practice in the absence of contracts, so that some contracts lack "additionality" (Mason and Plantinga 2013; Pattanayak, Wunder, and Ferraro 2010). A recognized but sparsely studied friction is the transaction cost incurred by contracting parties, which adds social costs to the realized level of services.

Transaction costs in contracting occur in many forms, including the costs of formulating, negotiating, and executing contracts, as well as the costs of monitoring and measuring actions during 
the contract period (Cacho, Marshall, and Milne 2005). While very few studies address PES contracts specifically, there exists an empirical literature on various types of transaction costs borne by government agencies and farmers in environmental programs (e.g., Falconer, Dupraz, and Whitby 2001a; McCann and Easter 1999; McCann 2009; Vernimmen 2000). This paper focuses on the transaction costs borne by agents in the PES contracting process and the associated impacts on aggregate outcomes. Previous studies have simulated the aggregate effects of transaction costs in PES schemes (e.g., Antle et al. 2007; Netusil and Braden 2001) but because of the paucity of empirical estimates, they usually model transaction costs as a constant price premium across all contracts sold. In this paper, we develop estimates of transaction costs that vary across agents, which allows for a varying premium.

Our estimates are based on a principal-agent framework, which captures the potential links between transaction costs and information asymmetries. To mitigate against noncompliance or "moral hazard," many PES contracts include provisions beyond a commitment to adopt a practice. Agents often face a detailed enrollment process before signing a contract, and by signing usually grant their consent to being monitored with penalties assessed for violations (Wunder, Engel, and Pagiola 2008). We model these provisions as a bundle of attributes an agent must accept with contract enrollment. More stringent provisions (e.g., increased inspection frequency) raise the likelihood of contract compliance but at the same time reduce the agent's utility of enrolling. To maintain the enrollment of the marginal agent, the principal must add a premium to payments to cover the transaction costs of the extra stringency. At an aggregate scale, contract stringency determines both the location and shape the contract supply curve. Heterogeneity across agents implies an upward sloping supply curve and contract stringency shifts the supply toward higher prices, although not necessarily in parallel fashion.

Our model also captures the second information asymmetry between the principal and agents. If agents hold private information on their reservation prices of contracting, the principal can only offer a uniform contract payment, which implies that at least some agents receive a payment 
exceeding their willingness-to-accept (WTA). These excess payments are known as information rents, which have been estimated to be a substantial share of payments in many existing programs (Ferraro 2008).

To fix ideas, we assume that the principal faces an exogenous enrollment target, and that the program objective is to maximize the net gains from the contracted acreage. Net gains are defined as environmental benefits, which depend on contract stringency through compliance effects, less payment expenditures, which are determined from the contract supply. The principal's problem is analyzed in two steps, where aggregate payment expenditures are derived as a function of contract stringency first, and then stringency is chosen by trading off environmental benefits against aggregate payments. A key result from the first step is that contract stringency generally affects both transaction costs and information rents. This implies that the principal can reduce aggregate expenditures by varying stringency, as an alternative to price discriminating on the basis of individual WTA. In the second step, we derive the implicit optimal frontier between stringency and contract compliance, which traces out the minimum change in compliance needed to justify an increase in stringency.

We apply our model to empirically assess the role of transaction costs in a hypothetical water quality trading market in Kansas. Our analysis is related to a recent literature that has analyzed contract enrollment decisions with stated choice data (Christensen et al. 2011; Espinosa-Goded, Barreiro-Hurlé, and Ruto 2010; Horne 2006; Hudson and Lusk 2004; Ma et al. 2012; Ruto and Garrod 2009; Vedel, Jacobsen, and Thorsen 2010). Similar to these works, we employ data from discrete choice experiments with landowners, where contract alternatives included price and nonprice attributes, and we analyze the resulting data with a mixed logit model. We depart from the existing literature, however, by estimating the full set of correlations among the coefficients in agents' utility functions. The estimated correlations are needed to capture the potential nonlinearities of shifts in contract supply. 
We then conduct a series of microsimulations of the estimated model to assess aggregate impacts. With our sample of farmers, we find that transaction costs account for a substantial portion of total payments, comparable in magnitude to information rents. We also find that the principal could significantly reduce information rents (as well as transaction costs) by relaxing contract stringency. In our setting, the simulated compliance frontier suggests that for plausible values of environmental benefits, very large increases in compliance are necessary to justify even moderate contract stringency levels.

\section{Conceptual Model}

Consider a principal who must set both the terms and prices of PES contracts to be offered to a large number of heterogeneous agents. A contract is specified by $(p, \mathbf{x})$, where $p$ is the contract payment for enrolling a fixed amount of land and $\mathbf{x}=\left(x_{1}, \ldots, x_{K}\right)$ is a set of nonprice attributes including eligibility requirements, noncompliance penalties, monitoring procedures, and other provisions.

Agents may be heterogeneous both with respect to their costs of committing to a contract and with respect to the environmental benefits from adopting the practice it requires (Ferraro 2003; Yang, Khanna, and Farnsworth 2005). In general, the principal may have and exploit agent-level information on both costs and benefits in the contracting process. However, we consider a pure practice-based program, in which payments are in exchange for practice adoption and do not depend on individual levels of environmental services. This accords with many PES schemes, which commonly do not attempt to measure the actual benefits provided by each agent (Wunder, Engel, and Pagiola 2008). Regarding costs, we consider alternative cases where the principal does and does not exploit agent-level information.

\section{Agents' Choices}

We first consider the agents' decisions. Each agent $n=1, \ldots, N$ makes a voluntary choice to enroll in at most one contract and, conditional on enrollment, decides whether to comply with its 
terms. Enrolling in a contract $(p, \mathbf{x})$ will yield an expected utility of

$$
U_{n}(p, \mathbf{x})=\max \left\{\alpha_{n} p-c_{n}(\mathbf{x}), \alpha_{n} p-v_{n}(\mathbf{x})\right\}
$$

where $\alpha_{n}$ is the agent's marginal utility of income, $c_{n}(\mathbf{x})$ is the expected disutility of complying with the contract, and $v_{n}(\mathbf{x})$ is the expected disutility of violating the contract. $c_{n}(\cdot)$ accounts for the costs of adopting the practice required by the contract as well as the disutility of complying with the terms in $\mathbf{x} . v_{n}(\cdot)$ accounts for the psychic and reputation costs of violation as well as the expected monetary expenses such as noncompliance penalties. Equation (1) implies that agent $n$ will comply as long as $v_{n}(\mathbf{x}) \geq c_{n}(\mathbf{x})$. We define the nonprice attributes as stringency-increasing, where greater stringency implies a higher cost of violating but also a higher cost of complying (i.e., $\partial c_{n} / \partial x_{k} \geq 0$ and $\partial v_{n} / \partial x_{k} \geq 0$ for all $\left.k\right)$.

To characterize the enrollment decision, the reservation utility of non-enrollment is normalized to $u_{0}=0$ for all $n$. The optimized utility of enrolling from equation (1) can be expressed as $U_{n}(p, \mathbf{x})=\alpha_{n} p-\phi_{n}(\mathbf{x})$, where $\phi_{n}(\mathbf{x}) \equiv \min \left\{c_{n}(\mathbf{x}), v_{n}(\mathbf{x})\right\}$ is the cost of the agent's optimal compliance/violation choice given the terms $\mathbf{x}$. Enrollment will then be optimal if $\alpha_{n} p-\phi_{n}(\mathbf{x}) \geq 0$, implying a decision rule that we express as

$$
y_{n}(p, \mathbf{x})= \begin{cases}1 & \text { if } p \geq \phi_{n}(\mathbf{x}) / \alpha_{n} \\ 0 & \text { if } p<\phi_{n}(\mathbf{x}) / \alpha_{n}\end{cases}
$$

where $y_{n}=1$ and $y_{n}=0$ indicate enrollment and non-enrollment, respectively. The term $\phi_{n}(\mathbf{x}) / \alpha_{n} \equiv \mathrm{WTA}_{n}(\mathbf{x})$ is defined as agent $n$ 's willingness-to-accept or minimum acceptable payment.

Heterogeneity in preferences across agents leads to a distribution of WTA, which in turn implies that the fraction of agents who enroll varies with contract payments and terms. The relationship between aggregate enrollment and varying combinations of $(p, \mathbf{x})$ can be regarded as a 
contract supply function. The properties of contract supply can be usefully analyzed with order statistics. ${ }^{1}$ Let $w(q, \mathbf{x})$ denote the $q^{\text {th }}$ order statistic of the distribution $\left\{\mathrm{WTA}_{n}(\mathbf{x})\right\}_{n=1}^{N}$. For a given set of attributes, $\mathbf{x}$, the vector $[w(1, \mathbf{x}), \ldots, w(N, \mathbf{x})]$ is the set of all agents' WTA values sorted in ascending order. We assume that each agent has a distinct WTA, so that the sorted values increase in a strictly monotone way for all $\mathbf{x}$; i.e., $w(1, \mathbf{x})<w(2, \mathbf{x})<\cdots<w(N, \mathbf{x}){ }^{2}$

The locus of points $\{(q, w(q, \mathbf{x}))\}$ then traces out the contract supply relationship. For simplicity, we assume that each contract enrolls a fixed amount of land (e.g., 100 acres) so the contract acreage supply is proportional to the contract supply. Note that the supply of environmental services depends on the pattern of heterogeneity in environmental benefits from the practice and compliance with the contract; we return to this issue below. Figure 1 depicts two contract supply relationships in the special case where WTA is uniformly distributed across a large number of agents, so that supply is closely approximated by a linear function. The two supply functions in the figure correspond to two different contractual terms that differ in stringency, $\mathbf{x}_{0} \ll \mathbf{x}_{1}$.

The relative locations of the two supply functions illustrates a general property of order statistics: if $\mathrm{WTA}_{n}\left(\mathbf{x}_{1}\right)>\mathrm{WTA}_{n}\left(\mathbf{x}_{0}\right)$ for all $n$, then $w\left(q, \mathbf{x}_{1}\right)>w\left(q, \mathbf{x}_{0}\right)$ for all $q$. Intuitively, this property means that increasing contractual stringency causes the supply relationship to shift toward higher prices. The size of the shift represents the transaction costs borne by agents, in the sense that increasing stringency from $\mathbf{x}_{0}$ to $\mathbf{x}_{1}$ requires a premium of $\tau \equiv w\left(q, \mathbf{x}_{1}\right)-w\left(q, \mathbf{x}_{0}\right)$ to be added to the payment in order to maintain the enrollment of $q$ agents. Figure 1 depicts a case where this premium is positively correlated with initial WTA; i.e., $\tau$ grows as $w(q ; \mathbf{0})$ increases along the supply locus. In this case $w\left(q, \mathbf{x}_{1}\right)$ has a steeper slope than $w\left(q ; \mathbf{x}_{0}\right)$. If this premium is negatively correlated with initial WTA, then $w\left(q, \mathbf{x}_{1}\right)$ is flatter than $w\left(q ; \mathbf{x}_{0}\right)$. The nature of such correlations and their effects on the shape of contract supply are empirical questions that we address in our application below. 


\section{Principal's Choice of Payments}

The principal's choices can be analyzed in two stages, where nonprice attributes are selected in the first stage and contract payment levels are set in the second stage. We analyze the problem by backward induction, starting with the second stage. The second-stage objective is to minimize aggregate expenditures on payments, conditional on the contract terms (x) set in the first stage, while meeting a target of enrolling $Q \in(0, N]$ agents. The value of $Q$ is assumed to be known and exogenous, determined from legislation or other predetermined program goals. ${ }^{3}$

The structure of the problem depends on the level of the principal's information on agents' individual WTA. We consider the polar cases of full information on individual agents and zero (aggregate only) information. In case of full information, the principal can perfectly price discriminate and offer a distinct price to each agent, leading to the problem

$$
\min _{p_{1}, \ldots, p_{N}}\left\{\sum_{n=1}^{N} p_{n} y_{n}\left(p_{n}, \mathbf{x}\right): \sum_{n=1}^{N} y_{n}\left(p_{n}, \mathbf{x}\right) \geq Q\right\}
$$

where $p_{n}$ is the payment offered to agent $n$. In the case of zero information, the problem is (3) with the additional constraint of a uniform price, i.e., $p_{1}=p_{2}=\cdots=p_{N}$. By letting $p$ denote the common price charged to all agents, the problem simplifies to

$$
\min _{p}\left\{p \sum_{n=1}^{N} y_{n}(p, \mathbf{x}): \sum_{n=1}^{N} y_{n}(p, \mathbf{x}) \geq Q\right\}
$$

We denote the solutions to problem (3) by $p_{n}(\mathbf{x})(n=1, \ldots, N)$ and the solution to (4) by $p(\mathbf{x})$. We also let $e_{\text {info }}(\mathbf{x})$ and $e_{\text {noinfo }}(\mathbf{x})$ denote the optimized value of the objective function, or minimum payment expenditures, in the cases of full and zero information, respectively.

In the case of full information, the principal will optimally enroll the set of agents with the lowest WTA to meet the enrollment target. These agents are precisely the group with a WTA at or below the $Q^{\text {th }}$ lowest value in the population, or those meeting the condition $\mathrm{WTA}_{n} \leq w(Q, \mathbf{x})$. 
The principal will optimally offer a price to each such agent following the rule of first-degree price discrimination. That is, the solution to problem (3) is

$$
p_{n}(\mathbf{x})=\mathrm{WTA}_{n}(\mathbf{x}) \quad \text { if } \mathrm{WTA}_{n}(\mathbf{x}) \leq w(Q, \mathbf{x}) .
$$

For the remaining high-cost agents (those with $\mathrm{WTA}_{n}>w(Q, \mathbf{x})$ ), the principal may offer any price strictly below WTA to dissuade them from enrolling. For the example in figure 1 when contractual terms are $\mathbf{x}=\mathbf{x}_{0}$, enrolled agents receive the varying prices along the curve $w\left(q, \mathbf{x}_{0}\right)$ to the left of the target $Q$. Total expenditures are then the accumulated area under $w(q, \mathbf{x})$ up to $Q$, i.e.,

$$
e_{\text {info }}(\mathbf{x})=\sum_{q=1}^{Q} w(q, \mathbf{x})
$$

which is area $D$ in figure 1 when contract terms are $\mathbf{x}_{0}$ and area $B+C+D$ when they are $\mathbf{x}_{1}$.

In the case of zero information, the optimal solution is a uniform price of $p(\mathbf{x})=w(Q, \mathbf{x})$ to all agents, implying optimized expenditures of

$$
e_{\text {noinfo }}(\mathbf{x})=Q w(Q, \mathbf{x})
$$

For contractual terms of $\mathbf{x}_{0}$, the smallest uniform payment that will enroll $Q$ agents is the value along the supply curve, $w\left(Q, \mathbf{x}_{0}\right)$, and the principal's total expenditures are the area $C+D$. For the more stringent terms $\mathbf{x}_{1}$, the uniform payment would need to be increased to $w\left(Q, \mathbf{x}_{1}\right)$, yielding total expenditures of $A+B+C+D$.

We can now define two measures that quantify the response of expenditures to changes in information and to contract stringency. First, information rents are defined as

$$
r(\mathbf{x}) \equiv e_{\text {noinfo }}(\mathbf{x})-e_{\text {info }}(\mathbf{x})
$$


or the reduction in expenditures between the polar cases of zero and full information. Because information rents arise from a given supply curve, they are a function of the stringency of contracts, $\mathbf{x}$. For the case of $\mathbf{x}=\mathbf{x}_{0}$ in figure 1, going from zero to full information reduces expenditures by $r\left(\mathbf{x}_{0}\right)=C$. Information rents with the more stringent contracts are $r\left(\mathbf{x}_{1}\right)=A$.

A second measure quantifies the stringency-induced transaction costs from the principal's point of view, holding the level of information fixed. Let

$$
t_{i}\left(\mathbf{x}_{0}, \mathbf{x}_{1}\right) \equiv e_{i}\left(\mathbf{x}_{1}\right)-e_{i}\left(\mathbf{x}_{0}\right)
$$

denote the increase in payment expenditures resulting from a change in contract terms from $\mathbf{x}_{0}$ to $\mathbf{x}_{1}$, where $i \in\{$ info, noinfo $\}$ denotes the level of information. In what follows we refer to this measure as the "additional transaction costs" due to a change in stringency. In the noinformation case in figure 1 , raising contract stringency from $\mathbf{x}_{0}$ to $\mathbf{x}_{1}$ raises payment expenditures from $e_{\text {noinfo }}\left(\mathbf{x}_{0}\right)=C+D$ to $e_{\text {noinfo }}\left(\mathbf{x}_{1}\right)=A+B+C+D$, implying additional transaction costs of $t_{\text {noinfo }}\left(\mathbf{x}_{1}, \mathbf{x}_{0}\right)=A+B$. In the full information case, additional transaction costs are $t_{\text {info }}\left(\mathbf{x}_{1}, \mathbf{x}_{0}\right)=$ $B+C$.

The relationships in figure 1 suggest that correlation patterns between the transaction cost premium $(\tau)$ and the supply curve create a dependency of information rents on contract stringency. For the case of linear relationships and positive correlation depicted in the figure, an increase in stringency from $\mathrm{x}_{0}$ to $\mathrm{x}_{1}$ not only generates additional transaction costs, but also changes information rents from $r\left(\mathbf{x}_{0}\right)=C$ to $r\left(\mathbf{x}_{1}\right)=A$. As noted above, the positive correlation causes the supply relationship for $\mathbf{x}_{1}$ to be more steeply sloped than that for $\mathbf{x}_{0}$, which implies that $A>C$. For nonlinear supply relationships, the interaction effects must be resolved empirically. We explicitly account for this correlation in our analysis below.

The dependence of information rents on stringency has important policy implications. Previous literature has shown that information rents can be large, but often schemes to price discriminate are 
practically difficult to implement and politically unappealing. If information rents can be reduced instead by relaxing stringency, the principal has a more politically feasible alternative that also has the benefit of lowering transaction costs. Of course, one concern with less stringent contracts is that compliance may decrease. This tradeoff is formalized in the principal's first-stage problem.

\section{Principal's Choice of Stringency}

In the first stage, the principal sets contract stringency, $\mathbf{x}$, accounting for the changes in payment expenditures as well as the changes in environmental benefits due to compliance effects. Let $b_{q}$ $(q=1, \ldots, Q)$ denote the potential environmental benefits obtained from the contracted practice for the agent in the $q^{\text {th }}$ position on the contract supply curve and let $\lambda_{q}(\mathbf{x})$ denote the expected share of benefits actually obtained given the agent's compliance effort. ${ }^{4}$ Total expected environmental benefits among the $Q$ agents enrolled is then $B(\mathbf{x})=\sum_{q=1}^{Q} b_{q} \lambda_{q}(\mathbf{x})=Q E\left[b_{q} \lambda_{q}(\mathbf{x})\right]$. The properties of $B(\mathbf{x})$ depends on the joint distribution of $b_{q}$ and $\lambda_{q}(\mathbf{x})$. In particular, the definition of covariance implies that expected benefits can be written

$$
B(\mathbf{x})=Q[\bar{b} \bar{\lambda}(\mathbf{x})+\sigma]
$$

where $\bar{b}=E\left[b_{q}\right]$ and $\bar{\lambda}(\mathbf{x})=E\left[\lambda_{q}(\mathbf{x})\right]$ are the means of benefits and compliance, respectively, for those agents that enroll in a contract and $\sigma$ is the covariance between benefits and compliance. Compared to the case where $b$ and compliance are uncorrelated $(\sigma=0)$, equation (10) reveals that a positive correlation implies higher expected benefits. This occurs because correlation causes the farmers with the highest potential environmental benefits to have the largest fraction of their benefits captured. ${ }^{5}$ We assume here that the covariance between benefits and compliance is fixed and does not depend on contract stringency. In the supplementary appendix, we show that results from the conceptual and empirical models differ little if the covariance is endogenous. 
Another relevant correlation is that between potential benefits and agents' WTA along the contract supply curve. This correlation affects the mean of potential benefits among the sub-population of agents enrolling in contracts, $\bar{b}$. As the sub-population of agents enrolling are those with the lowest WTA (figure 1), a positive (negative) correlation between WTA and potential benefits implies that the mean benefits among enrollees will be relatively low (high) compared to the overall mean. Thus, the $B(\mathbf{x})$ function will shift downward if the correlation between WTA and $b$ rises.

Using (10), the principal's first-stage problem with an information level of $i$ can be written

$$
\max _{\mathbf{x}} Q[\bar{b} \bar{\lambda}(\mathbf{x})+\sigma]-Q a(\mathbf{x})-e_{i}(\mathbf{x})
$$

where $a(\mathbf{x})$ is the principal's administrative cost of executing and enforcing a contract with a stringency of $\mathbf{x}$. The principal's objective is to maximize environmental benefits, net of of administrative costs and payment expenditures. In practice, there is considerable uncertainty around the solution to this problem because little is known about the component functions. ${ }^{6}$ However, information on the expenditure function, which is the empirical focus in this article, can be exploited to trace out the efficient frontier between stringency and mean compliance. In particular, changing stringency from $\mathbf{x}_{0}$ to $\mathbf{x}_{1}$ would increase the value of the objective function in (11) if

$$
Q\left[\bar{b} \bar{\lambda}\left(\mathbf{x}_{1}\right)-a\left(\mathbf{x}_{1}\right)\right]-e_{i}\left(\mathbf{x}_{1}\right)-\left(Q\left[\bar{b} \bar{\lambda}\left(\mathbf{x}_{0}\right)-a\left(\mathbf{x}_{0}\right)\right]-e_{i}\left(\mathbf{x}_{0}\right)\right)>0
$$

which reduces to

$$
\Delta \bar{\lambda}>\left[\frac{t_{i}\left(\mathbf{x}_{0}, \mathbf{x}_{1}\right)}{Q}+\Delta a\right] / \bar{b}
$$

where $\Delta \bar{\lambda}=\bar{\lambda}\left(\mathbf{x}_{1}\right)-\bar{\lambda}\left(\mathbf{x}_{0}\right)$ and $\Delta a=a\left(\mathbf{x}_{1}\right)-a\left(\mathbf{x}_{0}\right)$. The expression on the right side of (12) is a bound on the increase in mean compliance that a change in stringency must achieve. This bound 
is the ratio of the costs of the stringency change, $t_{i}(\cdot) / Q+\Delta a$, to mean environmental benefits, $\bar{b}$. The bound is a declining and convex curve when plotted against environmental benefits.

For some intuition, consider a simple example where an increase in stringency would create additional transaction costs per enrollee of $t_{i}(\cdot) / Q=\$ 30$. Initially suppose also that $\Delta a=0$; i.e., contract stringency has no effect on administrative costs. For environmental benefits of $\bar{b}=\$ 100$, the added stringency would need to satisfy $\Delta \bar{\lambda}>0.3$. As transaction costs represent $30 \%$ of potential benefits, an extra 3 out of every 10 farmers need to comply to capture enough new benefits to offset the new costs. If stringency does affect $a$, the condition becomes $\Delta \bar{\lambda} \geq 0.3+\Delta a / \bar{b}$. In the empirical analysis below, we generate points along the frontier in (12) from our estimates of the $t_{i}(\cdot)$ relations and other parameter values from the literature.

\section{Data}

Our data are from choice experiments representing contracting alternatives in a hypothetical water quality market. Our experiments were framed as a proposed market where municipal wastewater treatment plants could offset their discharges by buying PES contracts from farmers. Each plant could offer contractual payments and rules to suit its individual needs, generating a variety of contract offerings for farmers to consider.

\section{Experimental Design}

The attributes of the hypothetical contracts and the levels across which they were varied are in table 1 . The first attribute is represented by the vector of dummy variables $\mathbf{z}=($ FSnohay, FShay, NTcont, NTrot), where the single element of $\mathrm{z}$ equal to one in a given alternative indicates the contracted practice (e.g., $\mathbf{z}=(0,0,1,0)$ represents a contract requiring Continuous No-till). FSnohay and FShay represent two types of filter strips, a grass buffer area along a field edge that slows runoff and filters out sediments and nutrients. FSnohay is a filter strip that does not allow haying or grazing on the buffer area, while FShay permits both haying and grazing. NTcont represents 
Continuous No-till, where no soil tillage is permitted for the duration of the contract, and NTrot indicates Rotational No-till, where tillage is allowed for up to half of the contracted years. These practices were selected because they are relatively common and are easily understood by farmers, and are also known to be effective at increasing water quality. ${ }^{7}$

The remaining attributes are contractual terms. AppTime is the time requirement at contract initiation to go through the enrollment process; it was varied from 4 to 40 hours to reflect a wide range of enrollment complexity. InspectPr indicates the share of contract enrollees inspected for compliance each year, which was either $10 \%$ or $100 \%$. Penalty is a one-time fine to be paid if the farmer is found in violation of a contract, and was varied from $\$ 50 /$ acre to $\$ 500 /$ acre. Finally, the Payment attribute was varied from \$3/acre/year to \$25/acre/year, based on the ranges used by Cooper and Keim (1996) and Cooper (1997).

Subjects in the experiments were given booklets with a series of choice tasks, each task having three contract alternatives. For visual consistency and to reduce the number of attributes in our experimental design, the first alternative in every choice task was a contract requiring installation of a filter strip, the second was a contract requiring no-till, and the third alternative was a do-notenroll option. To facilitate comparison, subjects were told that all contracts had a 10-year duration and that the field being considered for enrollment was 100 acres in size. In addition, they were asked to assume that $(i)$ the land quality of the field was representative of their farm, (ii) the most recent tillage practice was minimum tillage (not no-till or conventional tillage), and (iii) the recent cropping pattern followed their typical crop rotation.

Prior to data collection, the attribute levels and data collection procedures were refined from meetings with cooperative Extension staff and a focus group with farmers. To construct the choice scenarios, we generated an orthogonal main effects design that varied all five attributes across the two contract alternatives (Adamowicz, Louviere, and Williams 1994). The smallest such design contained 32 scenarios, which were blocked into two sets of 16, giving us two versions of the experiment that were randomly assigned across subjects. 


\section{Sample Characteristics}

Data were gathered from groups of farmers attending Extension meetings at four locations in Kansas. Subjects were recruited at each meeting via a pre-registration mailing and an announcement at the opening conference session. The choice experiment itself was then conducted during a 1-hour session, typically scheduled with the help of the meeting organizers as a parallel session in a one-day program. Data were collected from 135 subjects across the four locations, providing a total of 2,177 usable choice observations. ${ }^{8}$ Additional details on data collection are in the supplementary appendix.

Table 2 provides descriptive statistics for the sample. The average responses to the choice scenarios in the top panel of the table indicate the choices were fairly balanced across the three alternatives in each choice set. Among all choice observations in the sample, a filter strip alternative was chosen $39 \%$ of the time, a no-till alternative $34 \%$ of the time, and the do-not-enroll alternative $27 \%$ of the time.

The bottom panel gives summary statistics of the respondents and their operations. The farmers in our sample have an average farm size of over 1,600 acres, which is larger than the averages reported in the 2007 Census of Agriculture (USDA 2009) for all Kansas farms (707 acres) and for all US farms (418 acres). Census data, however, include a large number of very small operations. Over 32 percent of Kansas farms in the 2007 Census were smaller than 100 acres, which would not be of sufficient scale to participate in the PES contracts considered here. The average Kansas farm in the 2007 Census is 1,322 and 1,543 acres for the sub-populations with sizes of at least 100 and 200 acres, respectively. Our average subject is actually about 400 acres smaller than the average farm in the Kansas Farm Management Association, an entity with 1,543 farm members providing data that are frequently used for policy analysis. Thus, while our sample is not representative of all farm sizes, it likely better represents those for which such contracts are feasible.

Because our sample was drawn from attendees at Extension conferences, deviations in operator characteristics from state state averages are not surprising. At 41.5 years, our average respondent is 
younger than the state census average of 57.7 years. $58 \%$ of our respondents indicated that farming is their primary occupation, compared to $47 \%$ of farmers in the state census data. Education levels are not reported in the Census of Agriculture, but USDA Agricultural Resource Management (ARMS) survey data (USDA-ERS 2011) indicates that $66 \%$ of US farm operators have at least a high-school level education and $25 \%$ have a college degree. Compared to these statistics our sample of farmers have substantially more education, with $100 \%$ and $64.9 \%$ having high school and college diplomas, respectively. Our sample also has more experience with conservation programs, with $45 \%$ having participated in the Conservation Reserve Program (CRP) and 30\% in the Environmental Quality Improvement Program (EQIP), compared to 16\% of ARMS respondents receiving conservation program payments.

The nature of our sample then, may have implications for the extent to which results are generalizable to a broader population. The transaction cost measurement literature suggests that our sample will produce an under-estimate of the transaction costs incurred by the average farmer. Education reduces information processing costs (Huffman 1974), thereby lowering the cost of identifying and enrolling in government programs (Falconer 2000; McCann 2009; Mettepenningen et al. 2007). Full time farmers are expected to incur lower transaction costs relative to part-time operators, who must divide their available time between off farm employment, farm operation, and administrative tasks such as program enrollment (McCann 2009). Finally, transaction costs of enrollment in programs has been found to have a strong learning-by-doing effect (McCann et al. 2005; Mettepenningen et al. 2007), implying that farmers who have enrolled in similar programs previously incur lower transaction costs from future enrollment. Overall, the characteristics of our sample likely strengthen our result that transaction costs comprise a significant portion of the cost of contracting. 


\section{Econometric Analysis}

Our econometric analysis is built on a random utility framework. Let $C_{s}$ denote the set of alternatives in choice scenario $s=1, \ldots, 16$. In our empirical specification of equation (1), subject $n$ 's utility from choosing contract alternative $j \in C_{s}$ in choice scenario $s$ is $U_{n j}=V_{n j}+\epsilon_{j}$, where $V_{n j}$ is the nonrandom portion of utility that can be modeled as a function of observed factors and $\epsilon_{j}$ is a random term representing unobserved factors. The modeled portion of utility is specified as

$$
V_{n j}=\alpha_{n} \text { Payment }_{j}+\gamma_{n}^{\prime} \mathbf{z}_{j}+\boldsymbol{\beta}_{n}^{\prime} \mathbf{x}_{j}
$$

where $\mathbf{z}_{j}=\left(\right.$ FSnohay $_{j}$, FShay $_{j}$, NTcont $_{j}$, NTrot $\left._{j}\right)$ indicates the contracted practice, $\mathbf{x}_{j}=\left(\right.$ AppTime $_{j}$, Epen $_{j}$, Annual $\left._{j}\right)$ is a vector of nonprice attributes, and $\boldsymbol{\theta}_{n} \equiv\left(\alpha_{n}, \boldsymbol{\gamma}_{n}, \boldsymbol{\beta}_{n}\right)$ are the utility coefficients to be estimated. The first element of $\mathbf{x}_{j}$ (AppTime) is taken directly from the choice experiments (table 1), while the remaining two are derived attributes. The second element is the interaction between inspection frequency and the penalty: Epen $=$ InspectP $r \times$ Penalty, or the expected penalty to be paid conditional on violating the contract. The third element, Annual, is a binary variable capturing the independent effect of increased inspections, where Annual = 1 if InspectPr $=1$ ("annual monitoring") and Annual $=0$ otherwise. These derived attributes allow us to separate two conceptually distinct effects of inspection probability on enrollment. To identify the parameters of the model we impose the normalization restriction that $V_{n j}=0$ for the do-not-enroll alternative. In sum, our empirical specification of utility captures the disutility of enrollment $\left(\phi_{n}(\cdot)\right.$ in the conceptual section) through the terms $\gamma_{n}^{\prime} \mathbf{z}_{j}+\boldsymbol{\beta}_{n}^{\prime} \mathbf{x}_{j}$. The elements of $\boldsymbol{\gamma}$ are practice-specific constants, while the elements of $\boldsymbol{\beta}$ represent the marginal utility of contract attributes. ${ }^{9}$ 


\section{Derived Estimates}

Given estimates of the utility coefficients, $\hat{\boldsymbol{\theta}}_{n}$, we can derive estimates of several other variables of interest. First, a point estimate of agent $n$ 's WTA for a particular contract is

$$
\mathrm{WTA}_{n}=-\frac{\hat{\boldsymbol{\gamma}}_{n}^{\prime} \mathbf{z}+\hat{\boldsymbol{\beta}}_{n}^{\prime} \mathbf{x}}{\hat{\alpha}_{n}} .
$$

The change in WTA in response to a change in the $k^{\text {th }}$ attribute in $\mathbf{x}$, or the marginal willingnessto-accept (MWTA) of $x_{k}$, can be estimated as

$$
\operatorname{MWTA}_{n k} \equiv \frac{\partial \mathrm{WTA}_{n}}{\partial x_{k}}=-\frac{\hat{\beta}_{n k}}{\hat{\alpha}_{n}} \text {. }
$$

MWTA measures the separate effect of each contract attribute on enrollment costs. The MWTA for each of the binary elements of $\mathbf{z}$ is $-\hat{\gamma}_{n l} / \hat{\alpha}_{n}$, which can be interpreted as agent $n$ 's expected cost of committing to the $l^{\text {th }}$ practice.

Under particular assumptions, the MWTA for expected penalties has a further interpretation as an indicator of an agent's compliance intentions. Let $\lambda_{n}$ denote agent $n$ 's subjective probability of complying with a contract if he/she were to enroll, which is assumed to differ across individuals but to remain constant across practices $(\mathbf{z})$ and contractual terms $(\mathbf{x})$ for each individual. A $\$ 1$ increase in Epen then imposes a cost of $\$ 1$ on an agent in the state of the world where the agent violates the contract (occurring with probability $1-\lambda_{n}$ ), and has a cost of zero otherwise, for an expected cost of $\$\left(1-\lambda_{n}\right)$. If agent $n$ is risk neutral, then MWTA $_{n, E p e n}=1-\lambda_{n}$ or $n$ 's subjective probability of violating contracts. If the agent is risk averse, then $\mathrm{MWTA}_{n, \text { Epen }}$ is an upper-bound estimate of the subjective violation probability. A complete derivation of these results is in the supplementary appendix.

It should be noted, however, that the assumption of fixed individual compliance rates is restrictive because it holds a farmer's compliance probability constant across across practices and across 
different stringency levels. Compliance may differ across practices because tillage and the width of a filter strip would be easy to monitor, but grazing a filter strip may be difficult to detect in a late-season inspection. Further, the probability of complying may rise if penalties or the inspection frequency increase. Given the structure of our data, we cannot identify the parameters of a function $\lambda_{n}(\mathbf{z}, \mathbf{x})$, separately from the utility coefficients, $\boldsymbol{\beta}$. Although our derived estimate of $\lambda_{n}$ cannot capture within-subject variation in compliance, it does capture the cross-sectional heterogeneity in farmers' ex ante uncertainty about their ability to comply, such as prior experience with the practice or uncertainty regarding future constraints on production (Vedel, Jacobsen, and Thorsen 2010).

\section{Mixed Logit Specification}

The utility coefficients were estimated with a mixed logit (MXL) model (Train 1998, 2003). The MXL model is one of the most general approaches to capture preference heterogeneity, in which coefficients are allowed to vary across subjects following a specified distribution. A limitation of the MXL model is that the researcher must specify a form for the coefficient distribution based on little guidance from theory. Here, our base specification is the multivariate normal distribution, i.e., $\boldsymbol{\theta} \sim \operatorname{MVN}(\boldsymbol{\mu}, \boldsymbol{\Sigma})$ where $\boldsymbol{\mu}$ is the mean vector of the coefficients and $\boldsymbol{\Sigma}$ is the covariance matrix. We specify the most general form of this distribution allowing for all pairwise correlations among the coefficients. While these correlations complicate estimation, they are relevant here because they may affect the shape of contract supply.

Although a common choice in applications of the MXL model, the normal distribution imposes a symmetric shape on the coefficient distribution and has unbounded support. These assumptions may not be valid for all coefficients. For example, the marginal utility of income $\left(\alpha_{n}\right)$ is expected to be bounded above zero for all agents. In addition, we might expect this (and other) coefficient distributions to be skewed if there are clusters of values near zero and a number of outliers spread over a long tail on one side of zero. As a robustness check, we also estimated the model where 
the coefficients with a theoretically expected sign were distributed lognormally while those with unrestricted signs were distributed normally (see the supplementary appendix). The distributional assumptions make little difference to our main conclusions, so we only present results here for the model with all coefficients normally distributed.

Estimation procedures for the MXL model are described by Train (2003) and Greene (2007). The model derives its name from the 'mixing' of the coefficient distribution in estimation with the utility error, $\epsilon_{j}$, which is assumed to follow an extreme-value type I distribution. The likelihood that a subject's utility is maximized under their observed choices then has a known form but must be integrated over the mixing distribution using simulation or other methods (Train 2003, p. 148151). We employed the maximum simulated likelihood method with NLOGIT 4.0 Greene (2007), with 150 draws taken from the coefficient distribution in each iteration. Coefficients are specified to vary across individuals but are fixed for a given individual across all choice scenarios.

\section{Estimation Results}

The estimated means and dispersions (standard deviations) of the utility coefficients from the base model are reported in table 3. Nearly all of these parameters were estimated with high statistical significance, evidence that the coefficient distributions are centered away from zero and also vary across individuals. The magnitudes of the estimates are difficult to interpret directly as they are measured in utility units. To aid in interpretation, the last column of the table reports the implied marginal WTA of each variable at the estimated means of the coefficients. The next section presents a more comprehensive analysis of the implied WTA distributions.

The estimated coefficient means have signs consistent with theory and previous studies. The mean subject is estimated to incur disutility from committing to a practice $(\hat{\gamma} \ll 0)$. The MWTA associated with the practice dummies represents the average farmer's perceived commitment costs, which range from $\$ 1.45 /$ acre to $\$ 9.43$ /acre across the four practices. The estimated cost of committing to less restrictive versions of the practices are smaller; filter strips are less costly when 
haying and grazing is allowed, and no-till is less costly when it can be adopted on a rotational basis. Consistent with previous findings (Broch and Vedel 2010; Espinosa-Goded, Barreiro-Hurlé, and Ruto 2010), these differences indicate that greater flexibility reduces agents' opportunity costs of committing to a practice.

The estimated mean of the coefficient on AppTime implies that the average farmer would need about $\$ 0.20$ /acre in additional annual income to be compensated for an extra hour of application time at contract inception. Given that a contract would enroll a 100-acre field and the payments would be received annually over a 10-year period, this estimate translates to an hourly compensation of about $\$ 150 /$ hour assuming the farmer discounts the income stream at a rate of 0.05 . This value seems large, but may partly reflect landowners' expectation of reporting requirements during the contract period if the enrollment process is complex, along with a strong aversion to paperwork.

The estimated mean coefficient for Epen implies a MWTA of about \$0.015/acre per dollar of expected penalties. As discussed above, under particular assumptions this result means that the average landowner places at most a $1.5 \%$ probability on violating contractual terms. This estimate is somewhat lower than the observed noncompliance rates in existing programs. Both citing USDA datasets, Cattaneo (2003) reported that $11 \%$ of the contracted practices in the EQIP program during the period 1997-2000 were not fulfilled, while Giannakas and Kaplan (2005) reported that 4\% of audited farmers receiving commodity payments in 1997 did not fulfill conservation compliance requirements. However, our estimate represents a farmer's subjective probability formed prior to enrollment, which may be influenced by psychological factors such as overconfidence in one's future performance or the desire to punish violators. Overconfidence has been found to be more prevalent among males (Estes and Hosseini 1988; Bhandari and Deaves 2006), who comprise the vast majority of our sample.

Finally, the negative MWTA of Annual implies that, holding all other attributes constant including expected penalties, the average subject prefers annual monitoring over a $10 \%$ spot check system. However, this interpretation assumes that all other regressors are constant, which implies 
that a change from a spot-check to an annual monitoring system would be accompanied by a 10fold decrease in the Penalty variable to keep Epen unchanged. If instead Penalty is held constant, then the MWTA of Annual at mean coefficients is $-\left(\hat{\beta}_{3}+0.9 \times \hat{\beta}_{2} \times\right.$ Penalty $) / \hat{\alpha} .{ }^{10}$ This value is negative when Penalty is less than \$204 but becomes positive for larger penalties, reaching a value of $\$ 4.08$ at Penalty $=500$, the maximum of that attribute in the choice experiments. These results are consistent with recent research suggesting that agents perceive both benefits and costs from monitoring of their actions, so that net benefits may differ in sign across different situations. ${ }^{11}$

While the means of the distributions generally conform with expectations, most of the coefficients have relatively large estimated dispersions, implying that a non-trivial share of individuals are estimated to have coefficients with the opposing sign as the mean. The implied percentage of subjects with negative coefficients are reported in the second-to-last column of table 3 . As discussed above, these patterns may arise partly from the unbounded support of the normal distribution. Another potential data problem is that preferences of a given subject may not remain stable as they complete a sequence of 16 choice tasks due to learning and/or fatigue effects (Savage and Waldman 2008). We ran alternative models that address both these issues, and found that our main findings were robust across models (see supplementary appendix).

The estimated correlation coefficients in table 4 reveal a number of important patterns. ${ }^{12}$ The practice specific constants are positively correlated with each other, indicating that farmers who can adopt one practice at low cost can also adopt other practices at low cost. The coefficient on Epen $\left(\beta_{2}\right)$ is positively correlated with all the practice constants, which, consistent with intuition, suggests that farmers who have a low subjective probability of violating a contract are also low-cost adopters. Also consistent with intuition, the correlation between the coefficients of Payment $(\alpha)$ and AppTime $\left(\beta_{1}\right)$ is negative and significant, indicating that farmers with a high marginal utility of income also have a high disutility of enrollment time. 


\section{Contract Simulations}

We conducted a series of microsimulations to quantify the market-level effects implied by our econometric estimates. Our simulations are numerical implementations of our conceptual model, yielding predicted points on the surface of the expenditure function $e_{i}(\mathbf{x})$, from which we can generate estimates of information rents and additional transaction costs. The statistical uncertainty around each point is quantified with Monte Carlo methods.

Each simulation predicts outcomes for contracts requiring a single practice. We ran two simulations, one for Continuous No-till contracts and the other for Filter Strip (no haying/grazing) contracts. These simulations are sufficient to capture the differences across practice types, as the two additional practices in our choice experiments are more flexible (and hence lower cost) versions of the simulated ones.

\section{Costs and Contract Payments}

We first simulated the outcomes in the second stage of the principal's problem, in which contract payments are set given contract supply relations, a fixed enrollment target, and a specified level of contract stringency. The inputs for each simulation include the following elements:

- The estimation results from the MXL model. These include the estimated coefficient means, $\hat{\boldsymbol{\mu}}$, and covariance matrix, $\hat{\Sigma}$, that reflect the pattern of preference heterogeneity across agents. In addition, to simulate the confidence intervals around the final outputs, the model requires estimates of the sampling variance around these point estimates. Letting $\hat{\delta}=$ $\operatorname{vec}(\hat{\boldsymbol{\mu}}, \hat{\boldsymbol{\Sigma}})$ denote the full set of (vectorized) parameters estimated, the simulations also use the matrix $\mathbf{V}=\operatorname{var}(\hat{\boldsymbol{\delta}})$, the maximum likelihood estimate of the sampling covariances surrounding the estimated parameters. 
- The enrollment target, $Q$. The simulation model inputs this target as the proportion $\bar{y} \in[0,1]$ of agents to be enrolled (i.e., $Q=\bar{y} N$ ). We specified a target of $\bar{y}=0.5$, which implies that the last agent enrolled has median preferences.

- The stringency level(s) of the contract. To be able to trace out a frontier for the first stage decision, we simulated four stringency levels represented by the attribute profiles, $\mathbf{x}$, in table 5. The first profile represents a base case where all attributes are set at the minimum values in the choice experiments, while the remaining profiles are intended to represent "low," "medium," and "high" stringency levels based on the range of estimates from the literature. ${ }^{13}$

The simulation follows a nested Monte-Carlo method based on $\mathrm{Hu}$, Veeman, and Adamowicz (2005). An 'inner' algorithm captures the variation in agent's costs and enrollment actions due to preference heterogeneity, while an 'outer' loop quantifies the statistical uncertainty in the inner simulation results. ${ }^{14}$ In the inner loop, a sequence of independent draws, $\left\{\hat{\boldsymbol{\theta}}_{1}, \ldots, \hat{\boldsymbol{\theta}}_{N}\right\}$, is taken from a $M V N(\hat{\boldsymbol{\mu}}, \hat{\boldsymbol{\Sigma}})$ distribution, where each draw $\hat{\boldsymbol{\theta}}_{n}$ represents the utility coefficients of an agent. For each agent, $\mathrm{WTA}_{n}$ is calculated for each of the four $\mathrm{x}$ profiles using equation (14). The $\mathrm{WTA}_{n}$ 's are then sorted in ascending order for each $\mathrm{x}$, generating the family of supply relationships in panels (a) and (b) of figure 2. For each supply curve, expenditures under full and zero information are calculated from equations (6) and (7), yielding the results in panels (c) and (d). Finally, information rents and additional transaction costs are calculated from (8) and (9), shown in panels (e) and (f). The simulation results are the empirical equivalents of the theoretical areas in figure 1, where areas are calculated as numerical integrals.

The 'outer' loop runs $m=1, \ldots, M$ iterations of the inner algorithm, each time perturbing the $M V N(\hat{\boldsymbol{\mu}}, \hat{\boldsymbol{\Sigma}})$ coefficient distribution with an error drawn from V. In effect, payments are simulated for $M$ agent populations, each of which has a slightly different distribution of preferences over its $N$ members. We set $M=N=10,000$ in both simulations. The bar heights in the middle 
and bottom panels of figure 2 are the means of the output across the $M$ perturbations, while the error bars represent $95 \%$ confidence intervals.

Panels (a) and (b) of figure 2 reveal that contract stringency has both first-order and secondorder effects on contract supply. The first order effect is that more stringent contracts shift the supply relationship toward higher prices, as expected. Although the attributes of more stringent contracts are not costly for all agents (table 3), the bulk of agents face higher costs, resulting in an upward shift. The second order effect is a reduction in supply elasticity - i.e., the supply curves become more steeply sloped as contracts become more stringent.

The results in panels (c)-(f) of figure 2 decompose the payments needed to enroll half of the agents in the respective practice. As explained in the conceptual section, information rents are the difference between simulated expenditures at zero and full information, while additional transaction costs are the difference between expenditures at a given stringency and those at Minimum stringency. At each stringency level, the heights of the two bars in panels (e) and (f) represent the potential reduction in payment expenditures from either $(i)$ eliminating information rents by using individual WTA information to price discriminate or (ii) reducing additional transaction costs by reducing contract stringency to the Minimum level. The additional transaction costs assume zero information, which we take to be the policy-relevant baseline.

Consistent with previous findings, simulated information rents were large in proportion to total payments in each scenario, ranging from $64 \%$ and $78 \%$ of zero-information payments. Thus, a potentially large fraction of payment expenditures could be avoided through the collection and use of information. We find here that additional transaction costs are of a comparably large magnitude, although they naturally depend on the assumed level of stringency. At Low stringency, additional transaction costs represent $18 \%$ and $32 \%$ of zero-information payments for the No-till and Filter Strip contracts, respectively, while at High stringency they account for $52 \%$ and $69 \%$ of initial payments for those contracts. 
From a baseline of highly stringent contracts and zero information, the principal has a similar scope to reduce payments through changes in contract design as through collecting information. Moreover, relaxing contract stringency reduces information rents as well as transaction costs. For example, by relaxing stringency of Filter Strip contracts from High to Low, information rents decline from $\$ 8.72$ to $\$ 4.55$ per enrolled acre (while at the same time transaction costs decline from $\$ 9.36$ to $\$ 1.94$ per enrolled acre). This interaction does not hold in general, but arises in our setting because of the estimated second-order effects of stringency as described above.

\section{Compliance Frontiers}

Even if stringent contracts result in larger payments, the principal may still prefer greater stringency if it raises environmental benefits through greater compliance. To quantify this effect, we simulated the results of the principal's first-stage problem, finding points along the frontier in equation (12). The value of $t_{i}\left(\mathbf{x}_{0}, \mathbf{x}_{1}\right) / Q$ in (12) was set at the simulated (zero-information) additional transaction costs in panels (e) and (f) of figure 2 , while $\bar{b}$ was varied across a range of values based on estimates

from the literature. ${ }^{15}$ As $\bar{b}$ is the mean potential benefit among enrolled (i.e., low-WTA) agents, the varying levels of this parameter represent different correlations between potential environmental benefits and WTA, with smaller (larger) values of $\bar{b}$ corresponding to positive (negative) WTAbenefit correlations.

Another parameter in (12) is the change in administrative costs. While substantial evidence exists that environmental programs involving many landholders are administratively costly (McCann and Easter 1999; Falconer, Dupraz, and Whitby 2001b; Wunder, Engel, and Pagiola 2008), we were unable to find quantitative estimates of the change in costs from the type of contract stringency changes modeled here. We set $\Delta a=0$ in our simulations, which generates frontiers with the lowest possible change in compliance needed for a given stringency change. The resulting frontiers, in figure 3, should thus be interpreted as lower bounds. 
Figure 3 shows the simulated frontiers only for No-till contracts, with each curve representing a change in stringency from Minimum to an alternative level. Results for the Filter Strip contracts are not shown as they are nearly identical, except that the likely range of benefits would not include values above $\$ 30 /$ acre. As described in the conceptual section, these frontiers also assume that the covariance between environmental benefits and compliance is fixed and does not depend on stringency. In the supplementary appendix, we develop a simulation framework where covariance is endogenous but find that our main results change little.

The frontiers reveal that highly stringent contracts must be very effective at raising compliance to be justified, particularly when mean benefits are low. For example, if environmental benefits are \$10/acre (which is slightly above the current reimbursement rates paid by the EQIP program in Kansas), then raising stringency from Minimum to Low, Medium, and High stringency raises net benefits if it improves compliance rates by at least 20, 55, and 94 percentage points, respectively. Even if environmental benefits are \$20/acre, then raising stringency from Minimum to Low, Medium, and High stringency must increase compliance rates by at least 10, 27, and 47 percentage points.

\section{Conclusions}

This article has identified the role of transaction costs in PES contracts that arise from stringency in nonprice contractual terms. Transaction costs may coexist with information rents, which arise from landowners' private information on their own costs of committing to a contract. In our empirical analysis, we find that additional transaction costs from increased contract stringency are of comparable magnitude to information rents. We do not, however, estimate the cost of actually collecting the WTA information in order to price discriminate, which would partly offset the payment savings represented by information rents. The substantive role of stringency-induced transaction costs suggests that careful attention to contractual provisions is warranted in the design of PES 
programs and markets. Transaction costs may partly explain the low participation rates observed in many environmental markets.

While much literature has devised methods, such as auctions or mechanism design, to reduce payments by inducing agents to voluntarily reveal WTA information, our findings suggest that relaxing contractual stringency is an alternative payment-reducing strategy. For the case studied here, less stringent contracts not only reduce transaction costs but also substantially reduce information rents. This interaction may not hold in general but is linked to the positive correlations between agents' costs of committing to practices and their costs of dealing with stringent contractual terms.

Of course, a primary disadvantage of relaxing stringency is that environmental benefits may be sacrificed if contract compliance rates fall. We show how the estimates of stringency-induced transaction costs can illuminate the tradeoff between reduced payments and reduced environmental benefits from lost compliance. For the case studied here, highly stringent contractual provisions would be preferred only if those provisions have strong effects on compliance or if the benefits of practices are very high.

A limitation of our empirical analysis is that our choice data are based on hypothetical responses from a non-random sample of farmers, which may limit the generalizability of our findings. However, there are a number of reasons to believe that the transaction costs incurred by representative farmers would be even larger than our estimates. First, to the extent that our subjects are not representative of the population, the transaction cost measurement literature suggests that costs of stringent contractual terms in our sample would be below average. Moreover, if our subjects exhibited social desirability bias in favor of enrolling, or were over-confident in their ability to benefit from hypothetical contracts, our estimated costs would lie below their actual costs.

Our focus here is on practice-based contracting, where the principal seeks to maximize expected environmental benefits, net of administrative and payments costs, from practices adopted on a fixed acreage. The contribution of such programs to social welfare depends on the correlation between benefits and WTA (Yang, Khanna, and Farnsworth 2005; Ferraro 2003). In particular, a 
positive correlation may imply that the low-WTA agents with the greatest incentive to enroll also provide the lowest benefits, thus reducing the welfare gain. As our framework already accounts for the benefit-WTA correlation, a natural extension would be to model a performance-based program where contracts are denominated in environmental services provided. Empirical analysis of such a setting, however, would require site-specific data on environmental benefits of practice adoption.

Our analysis suggests ways that contracts should be designed to be maximally effective. Contractual terms should be designed to balance the objectives of keeping transaction costs and administrative costs low while raising the incentives to comply. Perhaps because of the potentially high costs of appeals and litigation, USDA has a relatively low frequency of inspecting and auditing contracts, and has often declined to extract penalties when noncompliance is discovered (Cattaneo 2003; Claassen, Cattaneo, and Johansson 2008). Instead, they have focused on an enrollment process that clearly documents the feasibility of a practice. While these procedures may improve compliance rates, our results suggest that they also may raise transaction costs, as farmers are found to be very averse to enrollment time but would be less averse to frequent inspection or moderate penalties. Our framework can be applied to quantify transaction costs and the most effective contract designs using new data on different contracting schemes.

\section{References}

Adamowicz, W., J. Louviere, and M. Williams. 1994. “Combining Revealed and Stated Preference Methods for Valuing Environmental Amenities." Journal of Environmental Economics and Management 26(3):271-292.

Antle, J.M., S.M. Capalbo, K. Paustian, and M.K. Ali. 2007. "Estimating the Economic Potential for Agricultural Soil Carbon Sequestration in the Central United States Using an Aggregate Econometric-Process Simulation Model.” Climatic Change 80:145-171.

Bhandari, G., and R. Deaves. 2006. “The Demographics of Overconfidence.” The Journal of Behavioral Finance 7:5-11. 
Blackman, A., and R.T. Woodward. 2010. "User Financing in a National Payments for Environmental Services Program: Costa Rican Hydropower.” Environment for Development Discussion Paper Series No. EfD EP 09-03-REV, Resources for the Future, March.

Bliemer, M.C., and J.M. Rose. 2013. "Confidence intervals of willingness-to-pay for random coefficient logit models.” Transportation Research Part B: Methodological 58:199-214.

Broch, S.W., and S.E. Vedel. 2010. "Heterogeneity in Landowners' Agri-environmental Scheme Preferences." In Proceedings of the Economic Council Conference on Environmental Economics.

Cacho, O.J., G.R. Marshall, and M. Milne. 2005. "Transaction and Abatement Costs of Carbonsink Projects in Developing Countries." Environment and Development Economics 10:597-614.

Cattaneo, A. 2003. "The Pursuit of Efficiency and Its Unintended Consequences: Contract Withdrawals in the Environmental Quality Incentives Program.” Review of Agricultural Economics 25:449-469.

Chambers, R.G. 1992. “On the Design of Agricultural Policy Mechanisms.” American Journal of Agricultural Economics 74:646-654.

Choe, C., and I. Fraser. 1999. “Compliance Monitoring and Agri-Environmental Policy.” Journal of Agricultural Economics 50:468-487.

Christensen, T., A.B. Pedersen, H.O. Nielsen, M.R. Mørkbak, B. Hasler, and S. Denver. 2011. “Determinants of Farmers' Willingness to Participate in Subsidy Schemes for Pesticide-free Buffer Zones-A Choice Experiment Study.” Ecological Economics 70:1558-1564.

Claassen, R., A. Cattaneo, and R. Johansson. 2008. "Cost-effective Design of Agri-environmental Payment Programs: US Experience in Theory and Practice.” Ecological Economics 65:737-752.

Cooper, J.C. 1997. "Combining Actual and Contingent Behavior Data to Model Farmer Adoption of Water Quality Protection Practices.” Journal of Agricultural and Resource Economics 22:3043. 
Cooper, J.C., and R. Keim. 1996. "Incentive Payments to Encourage Farmer Adoption of Water Quality Protection Practices." American Journal of Agricultural Economics 78:54-64.

Defrancesco, E., P. Gatto, F. Runge, and S. Trestini. 2008. “Factors Affecting Farmers' Participation in Agri-environmental Measures: A Northern Italian Perspective.” Journal of Agricultural Economics 59:114-131.

Espinosa-Goded, M., J. Barreiro-Hurlé, and E. Ruto. 2010. "What Do Farmers Want From AgriEnvironmental Scheme Design? A Choice Experiment Approach.” Journal of Agricultural Economics 61:259-273.

Estes, R., and J. Hosseini. 1988. "The Gender Gap on Wall Street: An Empirical Analysis of Confidence in Investment Decision Making.” The Journal of Psychology 122:577-590.

Falconer, K. 2000. "Farm-level Constraints on Agri-environmental Scheme Participation: A Transactional Perspective." Journal of Rural Studies 16:379-394.

Falconer, K., P. Dupraz, and M. Whitby. 2001a. “An Investigation of Policy Administrative Costs Using Panel Data for the English Environmentally Sensitive Areas." Journal of Agricultural Economics 52:83-103.

- 2001b. "An Investigation of Policy Administrative Costs Using Panel Data for the English Environmentally Sensitive Areas.” Journal of Agricultural Economics 52:103-883.

Fang, F., K. Easter, and P. Brezonik. 2005. "Point-Nonpoint Source Water Quality Trading: A Case Study in the Minnesota River Basin." Journal of the American Water Resources Association 41:645-657.

Ferraro, P. 2008. “Asymmetric Information and Contract Design for Payments for Environmental Services.” Ecological Economics 65:810-821.

Ferraro, P.J. 2003. “Assigning Priority to Environmental Policy Interventions in a Heterogeneous World." Journal of Policy Analysis and Management 22:27-43.

Fraser, I.M. 1995. "A Analysis of Management Agreement Bargaining under Asymmetric Information.” Journal of Agricultural Economics 46:20-32. 
Frey, B.S., and R. Jegen. 2001. "Motivation Crowding Theory." Journal of Economic Surveys 15:589-611.

Giannakas, K., and J.D. Kaplan. 2005. "Policy Design and Conservation Compliance on Highly Erodible Lands." Land Economics 81:20-33.

Greene, W.H. 2007. NLOGIT 4.0 Reference Guide.

Hart, R. 2005. “Combating Moral Hazard in Agri-environmental Schemes: A Multiple-agent Approach.” European Review of Agriculture Economics 32:75-91.

Horne, P. 2006. "Forest Owners' Acceptance of Incentive Based Policy Instruments in Forest Biodiversity Conservation — A Choice Experiment Based Approach.” Silva Fennica 40:169-178.

Hu, W., M.M. Veeman, and W.L. Adamowicz. 2005. "Labeling Genetically Modified Food: Heterogeneous Consumer Preferences and the Value of Information.” Canadian Journal of Agricultural Economics 53:83-102.

Hudson, D., and J. Lusk. 2004. "Risk and Transactions Cost in Contracting: Results from a ChoiceBased Experiment.” Journal of Agricultural \& Food Industrial Organization 2.

Huffman, W.E. 1974. "Decision Making: The Role of Education.” American Journal of Agricultural Economics 56:85-97.

Latacz-Lohmann, U., and C. Van der Hamsvoort. 1997. "Auctioning Conservation Contracts: A Theoretical Analysis and an Application.” American Journal of Agricultural Economics 79:407418.

Ma, S., S.M. Swinton, F. Lupi, and C. Jolejole-Foreman. 2012. "Farmers' Willingness to Participate in Payment-for-Environmental-Services Programmes." Journal of Agricultural Economics 63:604-626.

Mason, C.F., and A.J. Plantinga. 2013. "The Additionality Problem with Offsets: Optimal Contracts for Carbon Sequestration in Forests.” Journal of Environmental Economics and Management 66:1-14. 
McCann, L., B. Colby, K. Easter, A. Kasterine, and K. Kuperan. 2005. "Transaction Cost Measurement for Evaluating Environmental Policies.” Ecological Economics 52:527-542.

McCann, L., and K. Easter. 2000. "Estimates of Public Sector Transaction Costs in NRCS Programs." Journal of Agricultural and Applied Economics 32:555-563.

McCann, L.M.J. 2009. "Transaction Costs of Environmental Policies and Returns to Scale: The Case of Comprehensive Nutrient Management Plans." Review of Agricultural Economics 31:561-573.

McCann, L.M.J., and K.W. Easter. 1999. "Evaluating Transaction Costs of Nonpoint Source Pollution Policies." Land Economics 75:402-414.

Mercer, D.E., D.M. Cooley, and K. Hamilton. 2011. Taking Stock: Payments for Forest Ecosystem Services in the United States. Forest Trends.

Mettepenningen, E., A. Verpecht, G.V. Huylenbroeck, M. D’Haese, J. Aertsens, and V. Vandermeulen. 2007. "Analysis of Private Transaction Costs Related to Agri-Environmental Schemes." Consolidated Report, ITAES WP 6.

Netusil, N.R., and J.B. Braden. 2001. "Transaction Costs and Sequential Bargaining in Transferable Discharge Permit Markets.” Journal of Environmental Management 61:253-62.

Nyborg, K. 2000. "Homo Economicus and Homo Politicus: Interpretation and Aggregation of Environmental Values." Journal of Economic Behavior \& Organization 42:305-322.

Ozanne, A. 2001. "Moral Hazard, Risk Aversion and Compliance Monitoring in Agrienvironmental Policy." European Review of Agriculture Economics 28:329-348.

Ozanne, A., and B. White. 2008. "Hidden Action, Risk Aversion and Variable Fines in Agrienvironmental Schemes." The Australian Journal of Agricultural and Resource Economics $52: 203-212$.

Pattanayak, S.K., S. Wunder, and P.J. Ferraro. 2010. "Show Me the Money: Do Payments Supply Environmental Services in Developing Countries?" Review of Environmental Economics and Policy 4:254-274. 
Peterson, J.M., and R.N. Boisvert. 2004. "Incentive-Compatible Pollution Control Policies under Asymmetric Information on Both Risk Preferences and Technology.” American Journal of Agricultural Economics 86:291-306.

Ruto, E., and G. Garrod. 2009. "Investigating Farmers' Preferences for the Design of Agrienvironment Schemes: A Choice Experiment Approach.” Journal of Environmental Planning and Management 52:631-647.

Savage, S.J., and D.M. Waldman. 2008. "Learning and Fatigue during Choice Experiments: A Comparison of Online and Mail Survey Modes." Journal of Applied Econometrics 23:351-371.

Spulber, D.F. 1988. “Optimal Environmental Regulation under Asymmetric Information.” Journal of Public Economics 35:163-181.

Train, K.E. 2003. Discrete Choice Methods with Simulation. New York: Cambridge.

—. 1998. "Recreation Demand Models with Taste Differences Over People." Land Economics 74:230-239.

USDA. 2009. “2007 Census of Agriculture: Summary and State Data.” Technical Report.

USDA-ERS. 2011. “Agricultural Resource Management Survey.” Technical Report.

Vedel, S.E., J.B. Jacobsen, and B.J. Thorsen. 2010. “Contracts for Environmental Goods and the Role of Monitoring for Landowners' Willingness to Accept." Selected paper, 4th World Congress of Environmental and Resource Economists, Montreal, Canada.

Vernimmen, T. 2000. “Transaction Cost Analysis of Outsourcing Farm Administration by Belgian Farmers." European Review of Agricultural Economics 27:325-345.

Wu, J., and B.A. Babcock. 1996. "Contract Design for the Purchase of Environmental Goods from Agriculture.” American Journal of Agricultural Economics 78:935-945.

Wunder, S., S. Engel, and S. Pagiola. 2008. “Taking Stock: A Comparative Analysis of Payments for Environmental Services Programs in Developed and Developing Countries." Ecological Economics 65:834-852. 
Yang, W., M. Khanna, and R. Farnsworth. 2005. "Effectiveness of Conservation Programs in Illinois and Gains from Targeting." American Journal of Agricultural Economics 87:1248-1255. 


\section{Notes}

${ }^{1}$ Let the set $S$ denote a sample containing $N$ values. The $q^{\text {th }}$ order statistic in this sample, $s(q)$, is the $q^{\text {th }}$-lowest value in the set $S$, such that $s(1) \leq s(2) \leq \cdots \leq s(N)$.

${ }^{2}$ This assumption does not have meaningful impacts on our results, but rules out the possibility of flat spots along the supply relationship that would lead to indeterminacies in the quantity of contracts supplied.

${ }^{3}$ As one example, the Conservation Reserve Program has a statutory cap on enrolled acreage.

${ }^{4}$ If compliance is binary, then $\lambda_{q}(\mathbf{x})$ represents the probability that the agent complies with the contractual requirements. More generally it captures the degree or rigor of compliance (e.g., the attention paid to seeding and maintenance of a filter strip), such that greater rigor captures a greater share of potential benefits.

${ }^{5}$ As a simple example, suppose that half of the enrolled agents have potential environmental benefits of $b=0$, while for the other half $b=\$ 100$. If the compliance rate is uncorrelated with benefits with a mean of $\bar{\lambda}=0.7$, then the expected total benefits captured is $B=\frac{Q}{2}(0) \bar{\lambda}+\frac{Q}{2}(100) \bar{\lambda}=0.35 Q$. However, if compliance is correlated with $b$ such that the conditional mean of compliance is $\bar{\lambda}^{0}=0.5$ in the zero-benefits group and $\bar{\lambda}^{1}=0.9$ in the high-benefits group, then total benefits are $B=\frac{Q}{2}(0) \bar{\lambda}^{0}+\frac{Q}{2}(100) \bar{\lambda}^{1}=0.45 Q$.

${ }^{6}$ This problem is not identical to maximizing restricted social welfare (where the restriction reflects enrollment of $Q$ agents), but its components can be interpreted in welfare terms. In particular, if known, the first term in (11) accurately captures social benefits, but in the case of zero information the second term over-estimates social costs because the portion of payments reflecting information rents is simply a transfer from the principal to agents. If full information is the starting point, however, the objective in (11) is equivalent to restricted welfare. In sum, the results from (11) misrepresent welfare under zero information, but the maximum error is represented by information rents.

${ }^{7}$ Filter strips have varying configurations and sizes. To maintain consistency in the experiment, we specified the filter strip as comprising 4 acres of the 100 acre field. Further, to make filter strips comparable to no-till, which may be implemented at zero or negative costs for many farmers, subjects were told to assume that they would be fully compensated for all installation, maintenance, and land rent costs on those 4 acres. The payment would then be compensation for the transaction costs of the contract plus the cost of managing the filter strip (avoiding use as a roadway, repairing and reseeding any eroded areas), and again for consistency with the no-till contract, the payment would be received on a per acre basis for all 100 acres.

${ }^{8}$ While our sample is small compared to numbers attainable with survey methods, the number of participants is similar to that of other studies using high-level subject interaction in laboratory experiments or personal interviews. For example, Defrancesco et al. (2008) used personal interviews with 139 farmers in Northern Italy to investigate participation in environmental programs. 
${ }^{9}$ Although we have some data on individual characteristics (table 2), we do not attempt to estimate their impact on utility. Our research objectives here only require estimation of the pattern of heterogeneity; the causes underlying these patterns is a substantive research question but lies outside the scope of this paper. A reviewer also correctly notes that our normalization of zero utility for the do-not-enroll option does not allow us to estimate the preference for or against enrollment separately from the practice constants and attribute coefficients. For example, if subjects prefer to enroll in contracts regardless of the practice or contract attributes, this preference would be confounded with the estimated parameters. Because of the construction of our experiments, however, we cannot specify a model to identify the enrollment preference as a distinct effect.

${ }^{10}$ This expression is obtained as the difference between estimated WTA (equation (14)) at Annual = 1 and Annual = 0, holding Penalty and all other variables constant.

${ }^{11}$ For PES contracts, an agent's cost would include the opportunity cost of time and administrative costs during additional monitoring visits, in addition to disutility from viewing monitoring as intrusive or as a signal of mistrust. Benefits would be perceived by farmers with socially-oriented preferences, who may regard monitoring as a means to uphold social norms of fairness (e.g., Nyborg 2000) or as supporting conscientious behavior (e.g., Frey and Jegen 2001). Our results suggest that the average farmer's benefits outweigh his costs if penalties are low, but the reverse is true when penalties are high.

${ }^{12}$ While not all correlation coefficients are statistically different from zero, we reject the null hypothesis uncorrelated coefficients at the $99 \%$ percent level of confidence.

${ }^{13}$ McCann (2009) found that livestock producers in Iowa and Missouri spend an average of 16.6 hours developing comprehensive nutrient management plans. Fang, Easter, and Brezonik (2005) and McCann and Easter (2000) found transaction costs in the range of $30 \%-40 \%$ of total costs for farmers involved in contracting and technical assistance schemes; as shown below, these estimates fall within the range of our simulation results across the different scenarios.

${ }^{14}$ This procedure fits within the broad class of Krinksy-Robb simulation methods to obtain confidence bounds on derived parameters, with most prominent alternatives in the literature being the Delta method (Bliemer and Rose 2013) and jackknifing or bootstrapping. While a number of previous studies, following Hu, Veeman, and Adamowicz (2005), have applied Krinsky-Robb methods to obtain confidence bounds of WTP/WTA in mixed logit models, we extend it here to obtain confidence bounds around various aggregate outcomes from an agent simulation model.

${ }^{15}$ Ranges of potential benefits in the central plains were developed for each practice from published estimates, where benefits include improved water quality, soil productivity, and dust reduction due to reduced soil erosion; soil carbon sequestration; and improved wildlife habitat. Benefit estimates range from $\$ 7$ to $\$ 54$ per enrolled acre per year for No-till and from $\$ 6$ to $\$ 30$ per enrolled acre per year for Filter Strips. The sources and assumptions underlying the 
estimates are described in the supplementary appendix. As another a point of reference, the current payment rates for Kansas in the Environmental Quality Incentives program (http://www.nrcs.usda.gov/wps/portal/nrcs/ main/ks/programs/financial/eqip) are $\$ 9.55$ per enrolled acre for No-till and, depending on the type of grass and land shaping requirements, from $\$ 8$ to $\$ 10.40$ per enrolled acre for Filter Strips ( $\$ 200$ to $\$ 260$ per acre of filter strip area, which we assume to be $4 \%$ of the protected area that is enrolled). 
Table 1: Choice Experiment Attributes and Levels

\begin{tabular}{lll}
\hline Attribute & Levels & Variable \\
\hline Practice required by contract & Filter Strip (no haying/grazing) & FSnohay \\
& Filter Strip (with haying/grazing) & FShay \\
& Continuous No-till & NTcont \\
& Rotational No-till & NTrot \\
Application Time (hours) & $4,16,24,40$ & AppTime \\
Inspection Probability $^{a}$ & $0.1,1$ & InspectPr \\
Penalty for Violations (\$/acre enrolled) & Penalty \\
Contract Payment $(\$ /$ acre enrolled) & $50,100,250,500$ & Payment \\
\hline
\end{tabular}

${ }^{a}$ Estimated models used the derived attribute Annual $=\{0$ if InspectPr $=0.1,1$ if $\operatorname{InspectPr}=1\}$

${ }^{b}$ Estimated models used the derived attribute Epen $=$ InspectPr $\times$ Penalty 
Table 2: Sample Summary Statistics

\begin{tabular}{|c|c|c|c|c|}
\hline Variable & Units & Observations & Mean & Std. Dev. \\
\hline \multicolumn{5}{|l|}{ Stated Choices } \\
\hline Filter Strip & Dummy & 2177 & 0.39 & 0.49 \\
\hline No-till & Dummy & 2177 & 0.34 & 0.48 \\
\hline Do not enroll & Dummy & 2177 & 0.27 & 0.44 \\
\hline \multicolumn{5}{|l|}{ Individual Characteristics } \\
\hline Acres owned & Acres & 135 & 824 & 1236 \\
\hline Acres rented & Acres & 135 & 804 & 1342 \\
\hline Male & Dummy & 134 & 0.810 & 0.39 \\
\hline Age & Years & 135 & 41.5 & 15.50 \\
\hline Education & Years & 97 & 15.1 & 2.00 \\
\hline Farming primary occupation & Dummy & 133 & 0.58 & 0.49 \\
\hline Participated in CRP ${ }^{a}$ & Dummy & 128 & 0.45 & 0.50 \\
\hline Participated in EQIP ${ }^{b}$ & Dummy & 124 & 0.30 & 0.46 \\
\hline
\end{tabular}

${ }^{a} \mathrm{CRP}=$ Conservation Reserve Program

${ }^{b} \mathrm{EQIP}=$ Environmental Quality Incentives Program 
Table 3: Estimated Coefficient Means and Dispersions

\begin{tabular}{|c|c|c|c|c|c|}
\hline \multirow[b]{2}{*}{ Coefficient } & \multirow[b]{2}{*}{ Variable } & \multicolumn{2}{|c|}{ Point Estimates (Std. Errors) } & \multirow{2}{*}{$\begin{array}{r}\text { Share with } \\
\text { Coef. }<0\end{array}$} & \multirow{2}{*}{$\begin{array}{r}\text { MWTA at } \\
\text { Coef. Means }\end{array}$} \\
\hline & & Mean & Dispersion & & \\
\hline$\gamma_{1}$ & FSnohay & $\begin{array}{c}-0.9762^{* * *} \\
(0.25961)\end{array}$ & $\begin{array}{l}1.98129^{* * *} \\
(0.28298)\end{array}$ & $68.2 \%$ & 3.718 \\
\hline$\gamma_{2}$ & Fshay & $\begin{array}{c}-0.38381 \\
(0.28228)\end{array}$ & $\begin{array}{l}2.46883^{* * *} \\
(0.29826)\end{array}$ & $56.2 \%$ & 1.522 \\
\hline$\gamma_{3}$ & NTcont & $\begin{array}{c}-2.37915^{* * *} \\
(0.33950)\end{array}$ & $\begin{array}{l}4.07034^{* * *} \\
(0.30468)\end{array}$ & $72.1 \%$ & 9.433 \\
\hline$\gamma_{4}$ & NTrot & $\begin{array}{c}-0.36600 \\
(0.31287)\end{array}$ & $\begin{array}{l}3.00210^{* * *} \\
(0.28147)\end{array}$ & $54.9 \%$ & 1.451 \\
\hline$\beta_{1}$ & AppTime & $\begin{array}{c}-0.04908^{* * *} \\
(0.00690)\end{array}$ & $\begin{array}{c}0.05365^{* * *} \\
(0.00925)\end{array}$ & $82.0 \%$ & \\
\hline$\beta_{2}$ & Epen & $\begin{array}{c}-0.00386^{* * *} \\
(0.00079)\end{array}$ & $\begin{array}{c}0.00635^{* * *} \\
(0.00118)\end{array}$ & $72.8 \%$ & 0.015 \\
\hline$\beta_{3}$ & Annual & $\begin{array}{c}0.70873^{* * *} \\
(0.22835)\end{array}$ & $\begin{array}{l}1.15870^{* * *} \\
(0.32147)\end{array}$ & $27.0 \%$ & -2.810 \\
\hline$\alpha$ & Payment & $\begin{array}{l}0.25220^{* * *} \\
(0.01552)\end{array}$ & $\begin{array}{l}0.14980^{* * *} \\
(0.01669)\end{array}$ & $4.6 \%$ & \\
\hline Observations & 2177 & & & & \\
\hline McFadden $\mathrm{R}^{2}$ & 0.413 & & & & \\
\hline AIC & 1.329 & & & & \\
\hline $\mathrm{BIC}$ & 1.444 & & & & \\
\hline
\end{tabular}

Note: Asterisks $\left({ }^{* * *}\right)$ denote statistical significance at the $99 \%$ confidence level 


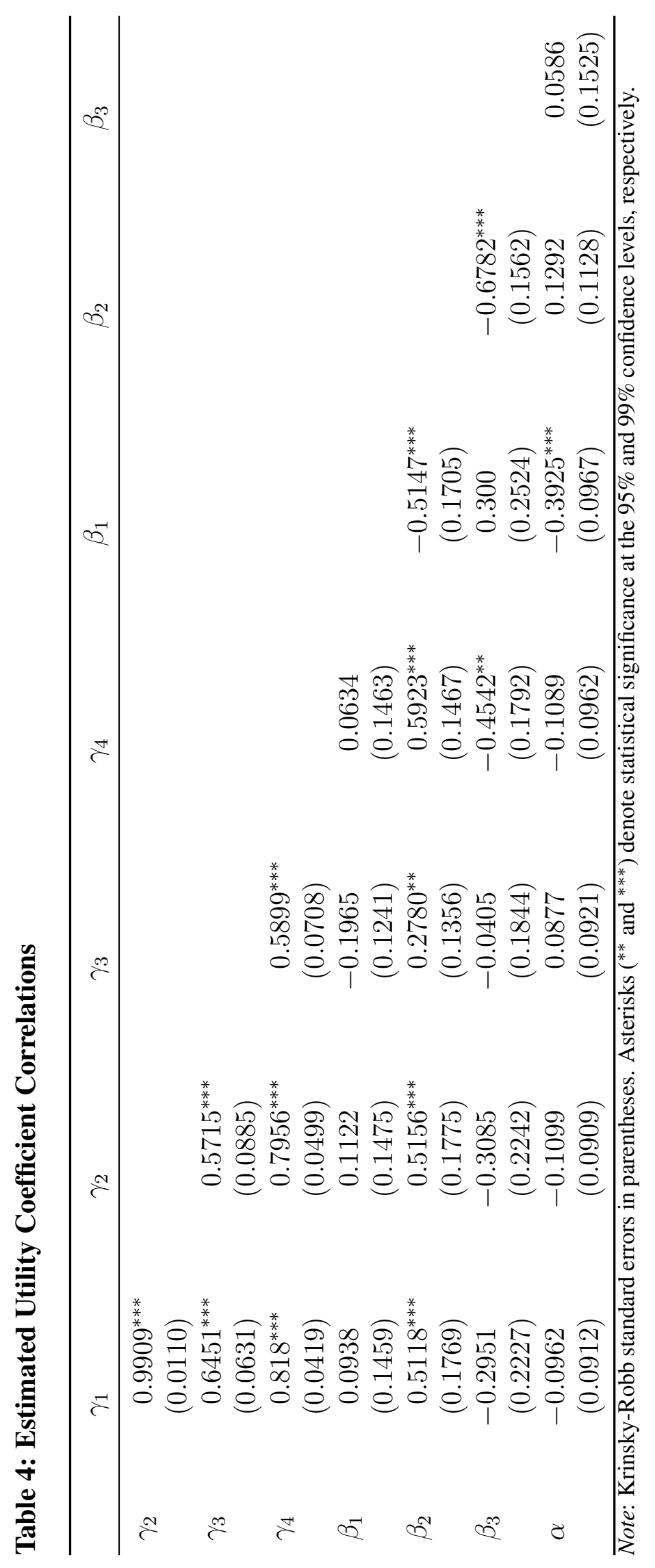


Table 5: Simulated Attribute Profiles

\begin{tabular}{lrrrr}
\hline & \multicolumn{4}{c}{ Stringency } \\
\cline { 2 - 5 } Attribute & Minimum & Low & Medium & High \\
\hline AppTime & 4 & 8 & 16 & 40 \\
Epen & 5 & 100 & 250 & 500 \\
Annual & 0 & 0 & 0 & 1 \\
\hline
\end{tabular}




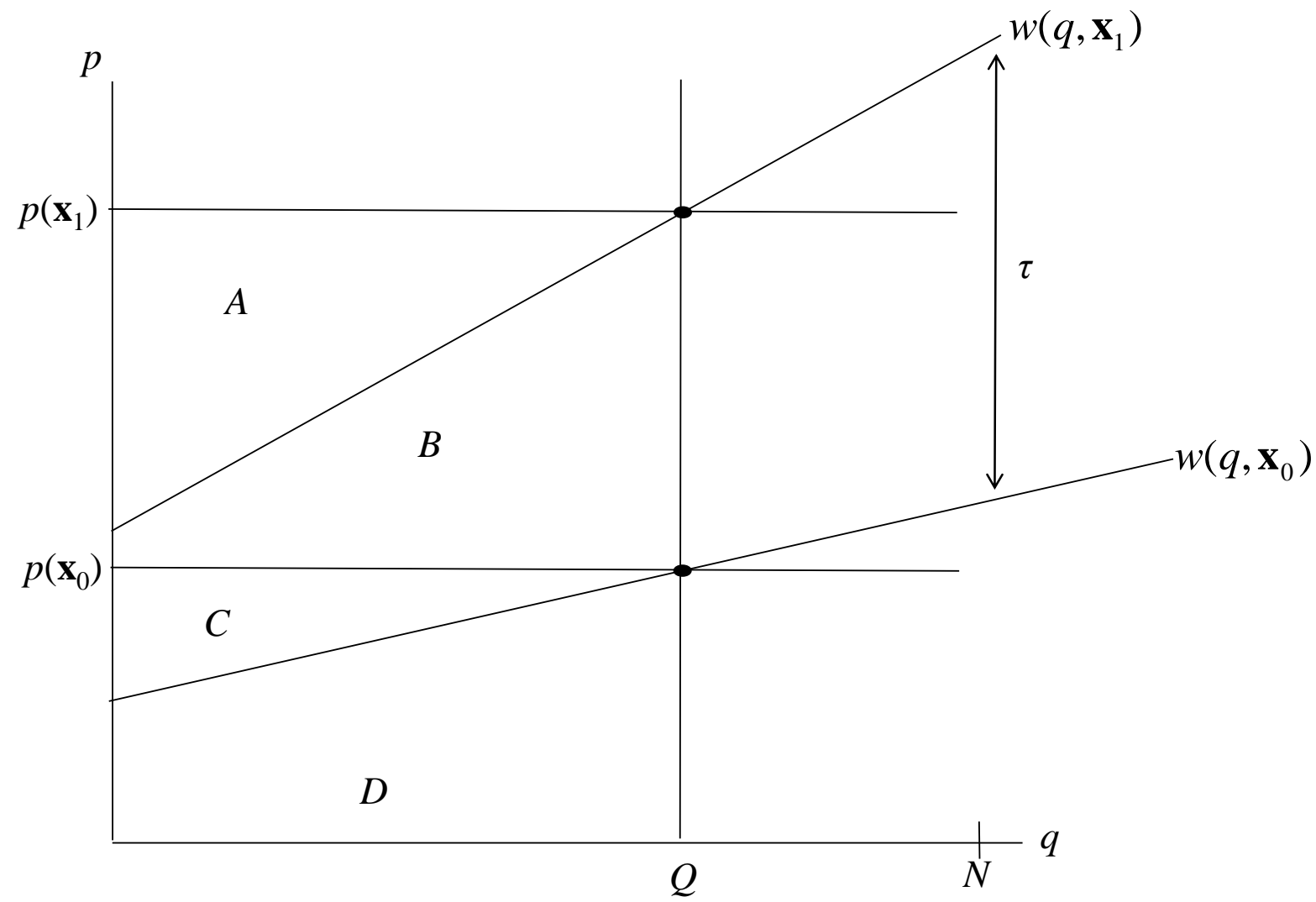

Figure 1: Contract supply and decomposition of aggregate payments 


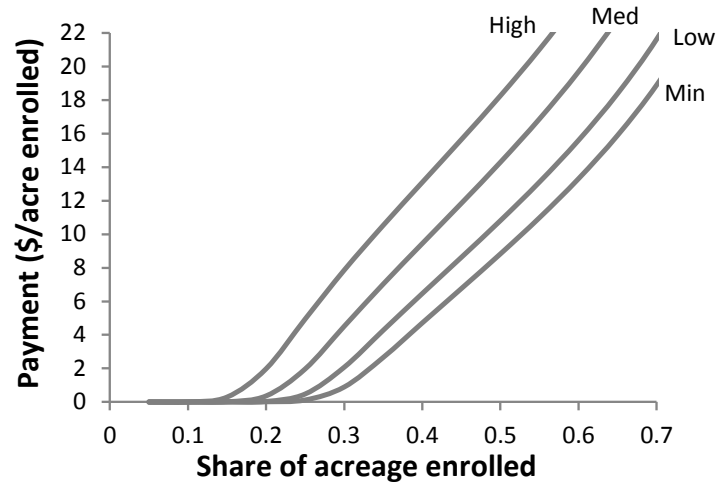

(a) Supply of no-till contracts, by stringency level

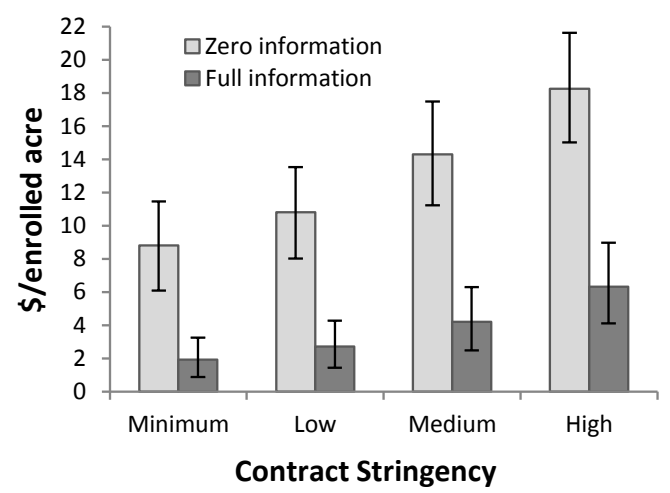

(c) Payment expenditures, no-till contracts

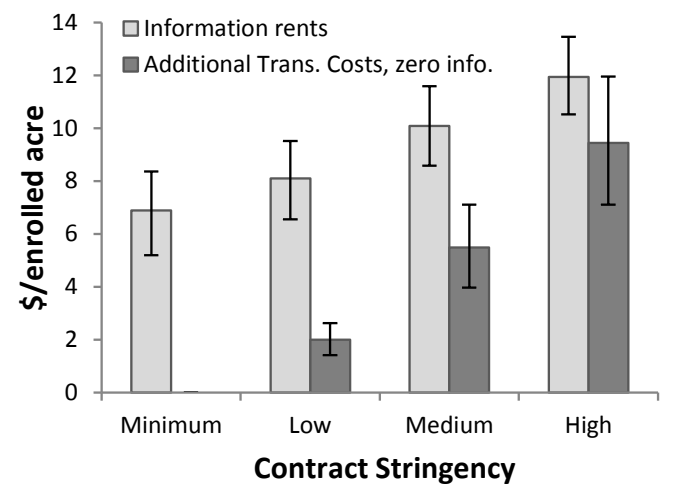

(e) Information rents and additional transaction costs, no-till contracts

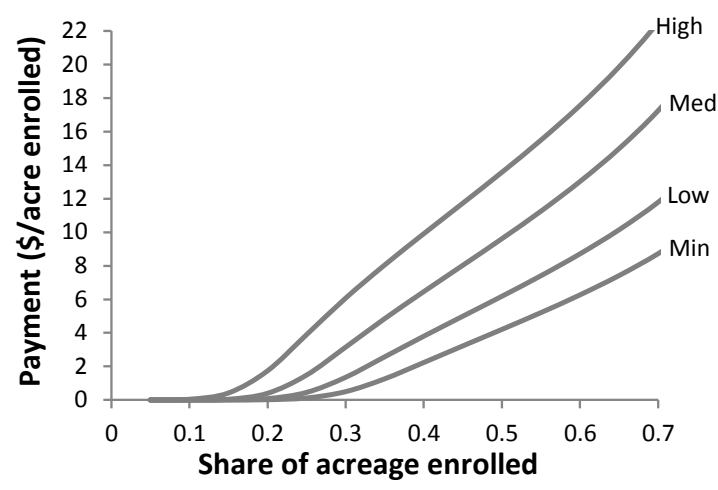

(b) Supply of filter strip contracts, by stringency level

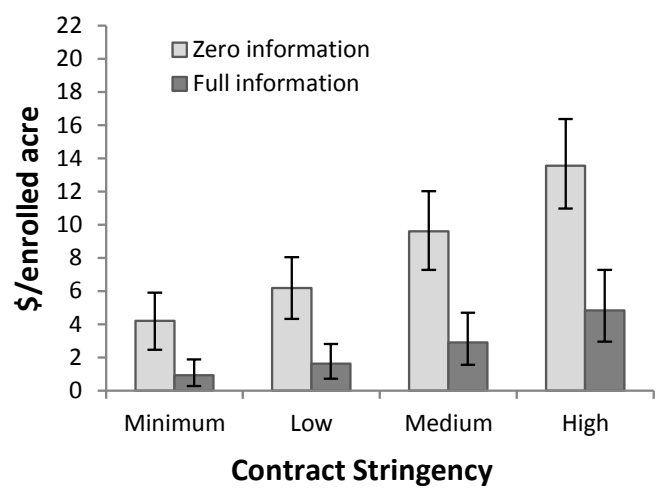

(d) Payment expenditures, filter strip contracts

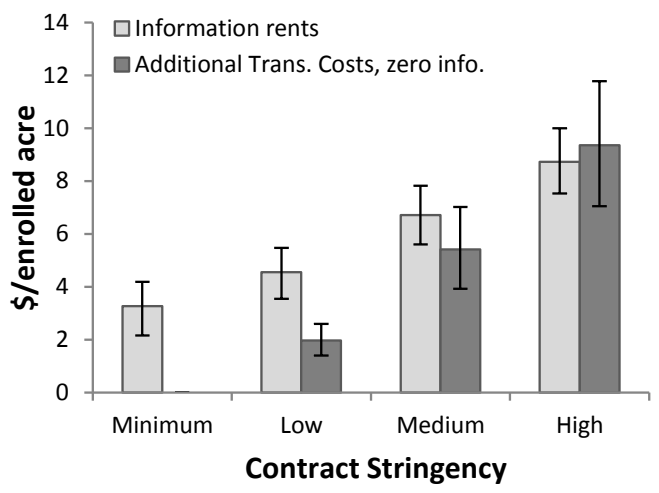

(f) Information rents and additional transaction costs, filter strip contracts

\section{Figure 2: Simulation results}

Note: Bar heights in panels (d) - (f) are simulated mean outcomes assuming an enrollment of $50 \%$ of eligible acreage from panels (a) and (b). Error bars indicate $95 \%$ confidence intervals. 


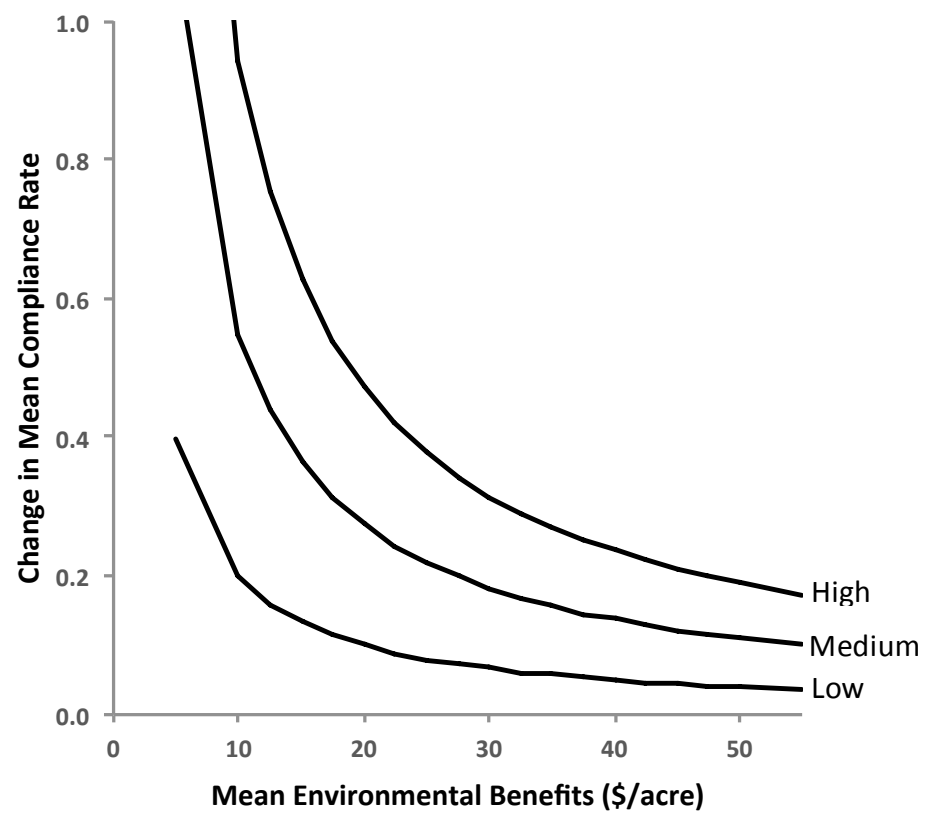

Figure 3: Simulated compliance frontiers for changes from Minimum stringency to alternative levels 